\title{
Temporal changes of abomasal contents and volumes in calves fed milk diluted with oral rehydration salt solution
}

\author{
Tamako MIYAZAKI ${ }^{1,2)}$, Keiji OKADA ${ }^{1)}$, Tetsuro YAMASHITA ${ }^{2)}$ and \\ Masao MIYAZAKI ${ }^{2) *}$ \\ ${ }^{1)}$ Department of Veterinary Medicine, Faculty of Agriculture, Iwate University, 3-18-8 Ueda, Morioka, \\ Iwate 020-8550, Japan \\ ${ }^{2)}$ Department of Biological Chemistry and Food Sciences, Faculty of Agriculture, Iwate University, \\ 3-18-8 Ueda, Morioka, Iwate 020-8550, Japan
}

J. Vet. Med. Sci.

81(2): 256-262, 2019

doi: $10.1292 / j v m s .18-0466$

Received: 6 August 2018

Accepted: 12 December 2018

Published online in J-STAGE:

3 January 2019

\begin{abstract}
Several manufacturers recommend to feed mixture comprising equal amounts of oral rehydration salt (ORS) solution and milk for diarrheic calves after milk withdrawal. Such a feeding method is expected to supply more nutrients and energy compared to feeding only the ORS solution. However, little is known about the effects of feeding milk diluted with ORS solution on calves' digestive process. This study examined the abomasal contents, volumes, and emptying rates in calves fed whole milk, milk diluted by $50 \%$ with ORS solution ( $50 \%$ ORS-milk), and ORS solution. Ultrasonography identified curds in the milk-fed calves, but not in the $50 \%$ ORS-milk-fed or the ORS-fed calves. The abomasal fluid of the 50\% ORS-milk-fed calves contained not only $\beta$-lactoglobulin but also a-casein (CN), $\beta-C N$, and $\mathrm{k}-\mathrm{CN}$, which were used for curd formation and undetectable in the milk-fed calves. Abomasal $\mathrm{pH}$ was relatively higher in the $50 \%$ ORS-milk-fed than that in the milk-fed calves. Abomasal emptying rates were significantly faster in the ORS-fed than in the 50\% ORS-milk-fed and the milk-fed calves. These data indicate that the formation of abomasal curd is inhibited in the 50\% ORS-milk-fed calves due to the resultant high abomasal pH and low $\mathrm{k}$-CN concentration. The 50\% ORS-milk may not provide rehydration as quickly as the ORS solution. In conclusion, we do not recommend feeding 50\% ORS-milk to calves.

KEY WORDS: abomasum, calf, curd formation, diarrhea, oral rehydration therapy
\end{abstract}


whether calves digest ORS-milk in the same manner as milk alone.

The abomasum is the only functional stomach from birth until about two weeks in calves. During this period, milk bypasses the rumen via the esophageal groove and flows directly to the abomasum that secretes chymosin to coagulate milk. Milk contents are separated into curd and whey. Curd formation is important for digestion and absorption of milk nutrients and immune substances in calves $[5,8,11,16]$. Previous studies showed that milk and milk replacers containing ORS had no effect on abomasal curd formation $[2,4,13]$. In contrast, the dilution of whole milk by $50 \%$ with ORS solution (50\% ORS-milk) inhibited curd forming in an in vitro assay [19], suggesting that no abomasal curd is formed in calves fed this $50 \%$ ORS-milk without direct evidence. Thus, the specific aim of the present study was to examine the effects of milk dilution with ORS solution, which is recommended by several manufacturers, on abomasal curd formation and abomasal emptying rate in calves. We compared temporal changes in abomasal contents and volumes between calves fed whole milk, ORS solution, and 50\% ORS-milk. Our results will contribute to improve our understanding of the digestive process of the current feeding method of diarrheic calves.

\section{MATERIALS AND METHODS}

\section{Whole milk, ORS solution, and 50\% ORS-milk}

Whole milk was obtained from a bulk tank containing fresh cows' milk with $4.53 \%$ fat, 3.59\% protein, and $8.85 \%$ solids-non-fat, which was certified quality of Ministerial Ordinance on Milk and Milk products Concerning Compositional Standards of Japan. The milk was stored at $4^{\circ} \mathrm{C}$ for up to 3 days before being fed to calves. The ORS solution used in the experiments was prepared by dissolving one Effydral tablet (48.71 g, Zoetis Japan, Tokyo, Japan) in $1 l$ of tap water according to the manufacturer's instruction. The tablet contained $2.34 \mathrm{~g}$ of sodium chloride, $1.12 \mathrm{~g}$ of potassium chloride, $6.72 \mathrm{~g}$ of sodium bicarbonate, $3.84 \mathrm{~g}$ of citric acid, $32.44 \mathrm{~g}$ of lactose, and $2.25 \mathrm{~g}$ of glycine, meaning that it contained bicarbonate at $80 \mathrm{mmol} / l$, citrate at $20 \mathrm{mmol} / l$, and a theoretical osmolality of $415 \mathrm{mOsm} / \mathrm{kg}$. The $50 \%$ ORS-milk was prepared by mixing equal amount of the whole milk and the ORS solution according to the manufacturer's instruction. The $\mathrm{pH}$ of solutions used in the experiments was measured by a pH meter (TPX-90, Toko Chemical Laboratories Co., Ltd., Tokyo, Japan) before feeding.

In vitro rennet coagulation tests were carried out to examine the curd forming property of the whole milk, the $50 \%$ ORS-milk, and the milk diluted by $50 \%$ with water (50\% water-milk), according to our previous study [16]. In brief, $10 \mathrm{~m} l$ of the whole milk, the $50 \%$ ORS-milk, and the $50 \%$ water-milk were incubated with rennet at $0.2-10 \mathrm{mg} / \mathrm{m} l$ for $2 \mathrm{hr}$ at $38^{\circ} \mathrm{C}$.

\section{Animals and feeding}

Three Holstein-Friesian calves with mean \pm standard deviation (SD) of BW at birth of $47.7 \pm 1.7 \mathrm{~kg}$ were used. Each calf was kept at a calf hutch and fed the first-milking colostrum at 4\% BW within $4.5 \mathrm{hr}$ after birth, and then fed fresh cow's whole milk at 6\% BW, using a bucket with a nipple, twice a day (at 8:00 and 20:00).

This study was conducted using a $3 \times 3$ Latin square design comprising the three calves between 6 and 16 day-old and following 3 solutions: whole milk, ORS solution, and 50\% ORS-milk. Treatment order was different in each calf, with a minimum washout period of at least $12 \mathrm{hr}$ between each treatment. Calves suckled each of the three solutions for 4 times at $12 \mathrm{hr}$ intervals from the bucket with a nipple. Solutions were fed to calves at $38^{\circ} \mathrm{C}$ and $6 \%$ of BW which was determined immediately before each treatment. Ultrasonographic observation was carried out after the fourth feeding for evaluating abomasal contents, volumes, and emptying rates. Calves had no access to water or calf starter ration during the treatment. This study was approved by the Animal Research Committee and followed the guidelines for Animal Experiment of Iwate University.

\section{Ultrasonography and estimation of abomasal volume and abomasal emptying rate}

Ultrasonography was performed according to a previous method [17], using a HS-1500V Ultrasonic system equipped with a HLS-375 5.0 MHz 50-mm linear transducer (Honda Electronics Co., Ltd., Toyohashi, Japan) before (pre), immediately (0), 0.5, 1, $1.5,2,4,6,8$, and $12 \mathrm{hr}$ after suckling started. Two or three sequential captured frames were combined into one picture to show abomasal contents in cross-sectional and longitudinal sectional images using Photoshop (Adobe Systems Inc., San Jose, CA, U.S.A.). Abomasal volume and emptying rate were calculated according to a previous report [30].

\section{Analysis of abomasal fluid}

The abomasal fluid was collected via abdominocentesis with an 18-gauge needle 0.5 and $2 \mathrm{hr}$ after suckling started, under local anesthesia with $2 \%$ procaine hydrochloride. Ultrasonography was used to confirm the optimal location for abdominocentesis, i.e., where the lumen of abomasum was largest and adjacent to the abdominal wall without disturbance of other organs. The pH of abomasal fluid was measured using a pH meter (TPX-90, Toko Chemical Laboratories Co., Ltd., Tokyo, Japan). Protein concentrations were measured by the Bradford method, using bovine serum albumin as the standard.

\section{$S D S-P A G E$}

Protein compositions of $10 \mu \mathrm{g}$ aliquot from the three feeding solutions, the liquid phase of the rennet coagulation test, and abomasal fluid obtained $2 \mathrm{hr}$ after feeding were analyzed by sodium dodecyl sulfate polyacrylamide gel electrophoresis (SDSPAGE, 10-20\% gel) under non-reducing conditions, and the gel was stained with Coomassie Brilliant Blue R-250 (CBB). CBB stained bands of $\alpha$-Casein $(\mathrm{CN}), \beta-\mathrm{CN}, \kappa-\mathrm{CN}$, and $\beta$-lactoglobulin (LG) were determined based on the previous report [16, 31 ]. 
Table 1. In vitro rennet coagulation test

\begin{tabular}{l} 
Concentration of rennet $(\mathrm{mg} / \mathrm{m} l)$ \\
\hline $10 \mathrm{~m} l$ whole milk
\end{tabular}

\section{Statistical analysis}

All data are expressed as means \pm SD. BW before and after the treatments were compared by paired $t$-tests. Abomasal volumes, $\mathrm{pH}$, protein concentrations, and emptying rates were compared among groups at the same time point and time-dependent changes within each group using one-way analysis of variance (ANOVA) and repeated measure ANOVA, respectively, followed by multiple comparison using the Tukey-Kramer honestly significant difference test. All statistical analyzes were performed on JMP12 software (SAS Institute, Cary, NC, U.S.A.), considering $P<0.05$ as significant.

\section{RESULTS}

\section{Different coagulation activities between milk and 50\% ORS-milk}

In vitro rennet coagulation tests using rennet at $0.2-10 \mathrm{mg} / \mathrm{m} l$ showed that curd was not produced in the $50 \%$ ORS-milk, while the whole milk and the $50 \%$ water-milk were coagulated using rennet at $0.2 \mathrm{mg} / \mathrm{ml}$ and $2 \mathrm{mg} / \mathrm{ml}$, respectively (Table 1 ). Protein concentrations in the whole milk, the 50\% ORS-milk and the ORS solution were $40.2,23.9$, and $0 \mathrm{mg} / \mathrm{ml}$, respectively. Figure 1 shows the protein compositions of the reaction mixtures before and after incubation of the 50\% ORS-milk or the $50 \%$ water-milk. $\alpha-\mathrm{CN}, \beta-\mathrm{CN}, \kappa-\mathrm{CN}$, and $\beta-\mathrm{LG}$ were the major contents in both samples before incubation. Although $\alpha-\mathrm{CN}, \beta-\mathrm{CN}$, and $\kappa-\mathrm{CN}$, but not $\beta$-LG, were not present in the liquid layer (whey fraction) of the $50 \%$ water-milk after incubation, these proteins were detected in the 50\% ORS-milk after incubation. These results indicated that curd was not formed from the 50\% ORS-milk in in vitro assays.

\section{Temporal changes of abomasal contents visualized by ultrasonography}

No physical problems were detected in calves during the experiments, and all calves suckled the entire volumes of the whole milk, the 50\% ORS-milk, and the ORS solution within $5 \mathrm{~min}$. No significant differences in BW before and after treatments were found in milk-fed calves $(48.9 \pm 1.9 \mathrm{~kg}$ and $50.3 \pm 2.3 \mathrm{~kg}$, respectively), and 50\% ORS-milk-fed calves $(50.3 \pm 2.0 \mathrm{~kg}$ and $50.7 \pm$ $2.2 \mathrm{~kg}$, respectively). There was a significant difference between BW before and after treatments $(49.6 \pm 2.4 \mathrm{~kg}$ and $48.5 \pm 2.2 \mathrm{~kg}$, respectively) in the ORS-fed calves.

Figure 2 shows representative ultrasonographic images of the abomasum before and after feeding. In all calves, the abomasum was visualized as an echogenic image in maximum volume immediately after feeding $(0 \mathrm{hr})$. In the milk-fed calves, the echogenicity of abomasal contents increased at the bottom of abomasum $0.5 \mathrm{hr}$ after feeding. Then, an echogenic image with clear outline, corresponding to a large curd, was observed between 1 and $2 \mathrm{hr}$ after feeding; this image became indistinct at $4 \mathrm{hr}$. On the contrary, the ORS-fed calves showed only anechoic images corresponding to ORS solution from 0.5 to $2 \mathrm{hr}$, and the contents gained echogenicity with gathering abomasal folds indicating almost no contents at $4 \mathrm{hr}$. In the 50\% ORS-milk-fed calves, there was no clear outlined image corresponding to curd. Echogenicity decreased until $1 \mathrm{hr}$ after feeding, but increased again after $4 \mathrm{hr}$. Images of abomasal contents were similar for all calves from $6 \mathrm{hr}$ after feeding to the end of the experiment.

\section{Protein contents of abomasal fluid}

The presence or absence of abomasal curd were also examined regarding the protein levels in the abomasal fluid samples obtained from calves $2 \mathrm{hr}$ after feeding. There were significant differences in protein concentrations of abomasal fluid samples between the $50 \%$ ORS-milk-fed calves $(10.8 \pm 0.1 \mathrm{mg} / \mathrm{m} l)$ and the milk-fed calves $(3.5 \pm 0.1 \mathrm{mg} / \mathrm{m} l)$ or the ORS-fed calves $(0.1 \pm$ $0.1 \mathrm{mg} / \mathrm{m} l$ ). In SDS-PAGE (Fig. 3), $\beta$-LG, but not $\alpha-\mathrm{CN}, \beta-\mathrm{CN}$, and $\kappa-\mathrm{CN}$, was detected as a major protein in the abomasal fluid of the milk-fed calves with curd formation. In contrast, $\alpha-\mathrm{CN}, \beta-\mathrm{CN}$, and $\kappa-\mathrm{CN}$ as well as $\beta$-LG were detected in the abomasal fluid of the $50 \%$ ORS-milk-fed calves.

\section{pH values of abomasal fluid}

The $\mathrm{pH}$ value of ORS $(7.2 \pm 0.2)$ was significantly higher than that of the whole milk $(6.7 \pm 0.1)$ and the $50 \%$ ORS-milk $(6.8 \pm$ $0.2)$. The $\mathrm{pH}$ of abomasal fluid samples $0.5 \mathrm{hr}$ after feeding were significantly lower in the milk-fed calves $(5.6 \pm 0.2)$ than in the $50 \%$ ORS-milk-fed calves $(6.4 \pm 0.1)$ or the ORS-fed calves $(6.6 \pm 0.2)$. The $\mathrm{pH}$ of samples $2 \mathrm{hr}$ after feeding were significantly lower in the milk-fed calves $(4.8 \pm 0.1)$ than in the $50 \%$ ORS-milk-fed calves $(6.1 \pm 0.1)$ or the ORS-fed calves $(6.3 \pm 0.2)$.

\section{Temporal changes of estimated abomasal volume}

There was no significant difference on the feeding volumes of the 50\% ORS-milk-fed calves $(3,012.0 \pm 120.0 \mathrm{~m} l)$, the milk-fed 
calves $(2,932.0 \pm 111.5 \mathrm{~m} l)$, and ORS-fed calves $(2,976.0 \pm 141.5 \mathrm{~m} l)$. Figure 4 shows the temporal changes in estimated abomasal volume in the three groups. Remarkable increases of abomasal volumes were observed in all calves immediately after feeding. The volume was significantly larger between 0 and $4 \mathrm{hr}$ than before feeding in all calves. There was no significant difference in abomasal volume between the milk-fed and the 50\% ORS-milkfed calves. In contrast, the abomasal volume was significantly lower in the ORS-fed calves than in the milk-fed calves at $1,1.5$, and $2 \mathrm{hr}$, and the $50 \%$ ORS-milk-fed calves at $2 \mathrm{hr}$.

\section{Abomasal emptying rate}

Abomasal emptying rates measured by estimating abomasal emptying half time (T50) calculated from abomasal volume were $113.5 \pm 14.6 \mathrm{~min}$ in the $50 \%$ ORS-milk-fed calves, $113.5 \pm 11.5 \mathrm{~min}$ in the milk-fed calves, and 70.5 $\pm 12.2 \mathrm{~min}$ in ORS-fed calves.

\section{DISCUSSION}

This study demonstrated the effects of diluting milk with an ORS solution on the digestive process in calves by a comparison with that of milk and ORS solution. A major finding was the absence of curd in the $50 \%$ ORSmilk-fed calves. Although we did not directly evaluate secretion amounts and enzymatic activities of chymosin in each calf, ultrasonography showed that the same calves produced a large curd after feeding on the whole milk. Considering $\alpha-\mathrm{CN}, \beta-\mathrm{CN}$, and $\kappa-\mathrm{CN}$ were used for curd formation and were not present in the abomasal fluid $2 \mathrm{hr}$ after the ingestion, we strongly suggest that the 50\% ORS-milk-fed calves did not form abomasal curd as the milkfed calves did. These indirectly indicate that their abomasa had sufficient ability to form curd by chymosin during the experimental period. We suggest that the lack of curd formation in the 50\% ORS-milk-fed calves was caused by dilution of the milk with the ORS solution and not by abomasal dysfunction, as reported previously $[8,18]$.

We speculate that high abomasal $\mathrm{pH}$ resulting from the 50\% ORS-milk was the primary cause for the lack of curd formation in the calves. Abomasal curd formation begins with the hydrolysis of $\kappa-\mathrm{CN}$ by chymosin, which is secreted as an inactive proenzyme, prochymosin, that is activated upon exposure to acid [22]. The optimum $\mathrm{pH}$ for chymosin is 5.3-6.3 [7]. Calves fed the whole milk ( $\mathrm{pH}$ 6.7) exhibited a remarkable decrease in abomasal $\mathrm{pH}$, to 5.6 and 4.8, within 0.5 and $2 \mathrm{hr}$, respectively, after feeding, whereas calves fed the 50\% ORS-milk (pH 6.8) varied slightly, with $\mathrm{pH}$ of 6.4 and 6.1 at 0.5 and $2 \mathrm{hr}$, respectively, after feeding. Previous studies reported that abomasal pH was higher in the ORS-milk-fed calves than in the milk-fed calves due to the presence of alkalizing agents, such as bicarbonate and citrate [4]. Thus, feeding milk diluted with ORS solution containing alkalizing agents increases abomasal $\mathrm{pH}$ in calves, and the high abomasal $\mathrm{pH}$ causes insufficient chymosin hydrolytic activity, resulting in no curd formation.

In contrast to our results, other studies have reported that calves fed milk containing ORS produced abomasal curd [4, 13]. We think that these conflicting results might be due to different ways of dissolving the ORS. The previous studies used milk in which ORS powder was directly dissolved without being diluted with water, whereas we diluted the milk with an ORS solution. The final concentrations of bicarbonate and citrate in the 50\% ORS-milk used in this study were 40 and $10 \mathrm{mmol} / l$, respectively, similar to values reported in previous studies: $25 \mathrm{mmol} / l$ bicarbonate and $12 \mathrm{mmol} / \mathrm{l}$ citrate [4], and $63 \mathrm{mmol} / \mathrm{l}$ bicarbonate or $93 \mathrm{mmol} / \mathrm{l}$ bicarbonate without citrate [13]. Therefore, the concentrations of alkalizing agents could not explain the cause for no curd formation in the 50\% ORS-milk-fed calves. Here, we suggest that diluting milk with ORS solution is a secondary reason for the lack of curd formation in the calves. It has also been reported that $\kappa-\mathrm{CN}$ concentration in milk is a key factor in curd formation [9]. In general, kinetics explains that a low $\kappa-\mathrm{CN}$ concentration decreases the maximum rate of the chymosin reaction (Vmax). This study showed that a 10 -fold higher concentration of chymosin was necessary to coagulate the milk diluted to $50 \%$ with water rather than the whole milk. Related studies have reported that the time for curd to form was significantly prolonged in the $50 \%$ watermilk mixture than in the whole milk [19]. These results suggest that not only high abomasal pH but also a low $\kappa-\mathrm{CN}$ concentration caused by diluting the milk with ORS solution had a negative effect on abomasal curd formation in the $50 \%$ ORS-milk-fed calves.

Many calves are fed milk replacer instead of milk. There are both curd forming and non-curd forming milk replacers [10, 21], and abomasal curd formation is influenced by the curd forming properties of the milk replacer. Since this study focused on the effects of ORS solution used to dilute milk on abomasal curd formation, we primarily tested ORS-milk and not ORS-milk replacer. We believe that both the alkalizing agents contained in ORS and dilution of the milk replacer inhibit curd formation in calves fed 
A

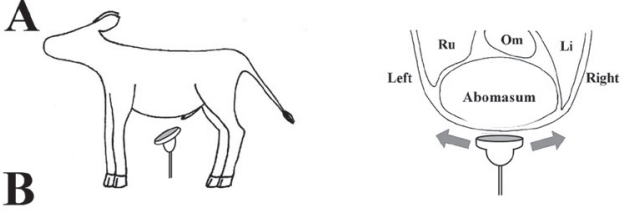

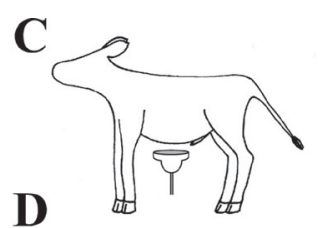

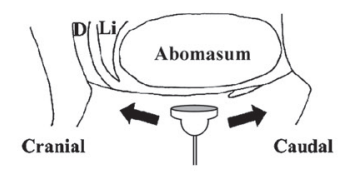

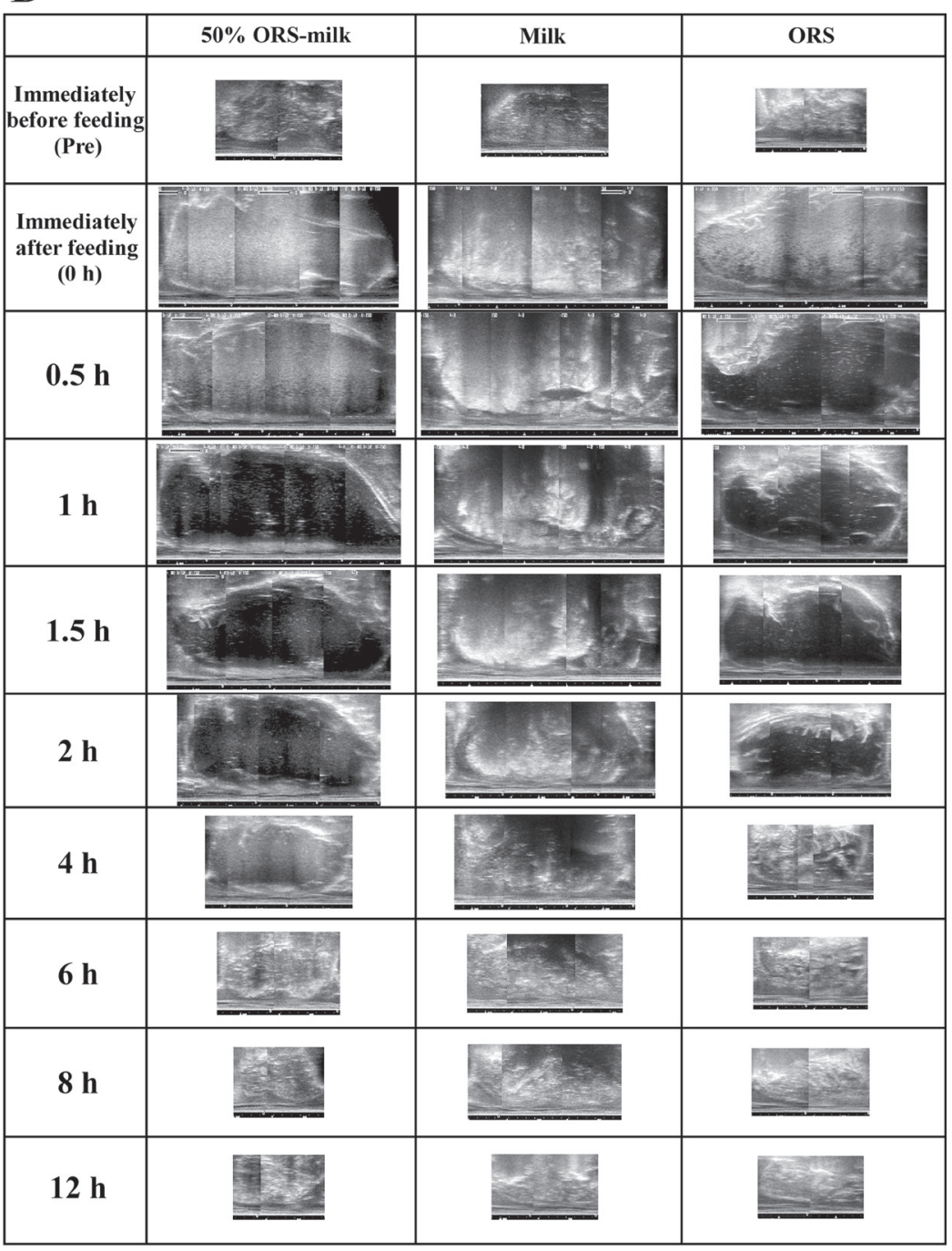

Fig. 2. Ultrasonographic images of the abomasal contents in a calf fed milk diluted by $50 \%$ with oral rehydration salt (ORS) solution (50\% ORS-milk), whole milk (Milk), and ORS solution (ORS). A: Left schematic representation shows how to visualize cross-sectional images of the abomasum by the ultrasonography. The transducer was placed transversely across the ventral midline to determine transverse plane of the abomasum. Right schematic representation explains the cross-sectional ultrasonographic images. Rumen (Ru), omasum (Om), and liver (Li). B: The cross-sectional ultrasonographic images of a calf fed 50\% ORS-milk (3.1 l), whole milk (3.0 $l$ ), and ORS solution (2.9 $l$ ), at 16-, 13-, and 11-days old, respectively. Upper, lower, right and left of images correspond to dorsal, ventral, right and left of the calf body, respectively. C: Left schematic representation shows how to visualize longitudinal-sectional images of the abomasum by the ultrasonography. The transducer was placed along the ventral midline to determine sagittal planes of the abomasum. Right schematic representation explains the longitudinal-sectional ultrasonographic images. Diaphragm (D) and liver (L). D: The longitudinal-sectional ultrasonographic images of the abomasal contents corresponding to Fig. 2B. A bar shows $15 \mathrm{~cm}$.

ORS-milk replacers, as with ORS-milk.

Previous studies have reported that ultrasonography can measure abomasal volume [30] and evaluate abomasal curd formation [17] in calves. This study also showed that ultrasonography is useful for monitoring postprandial changes in abomasal contents and volumes, which determine the presence or absence of abomasal curd formation and abomasal emptying half time, respectively, in calves. In contrast to analyzes of abomasal fluid that was sampled via a cannula attached by surgery [2, 4] and a post-mortem visual inspection $[5,6,23]$, ultrasonography is a non-invasive method that can be used to observe abomasal contents and volumes repeatedly in the same individual. We propose that ultrasonographic observations should be applied to clinical cases exhibiting 


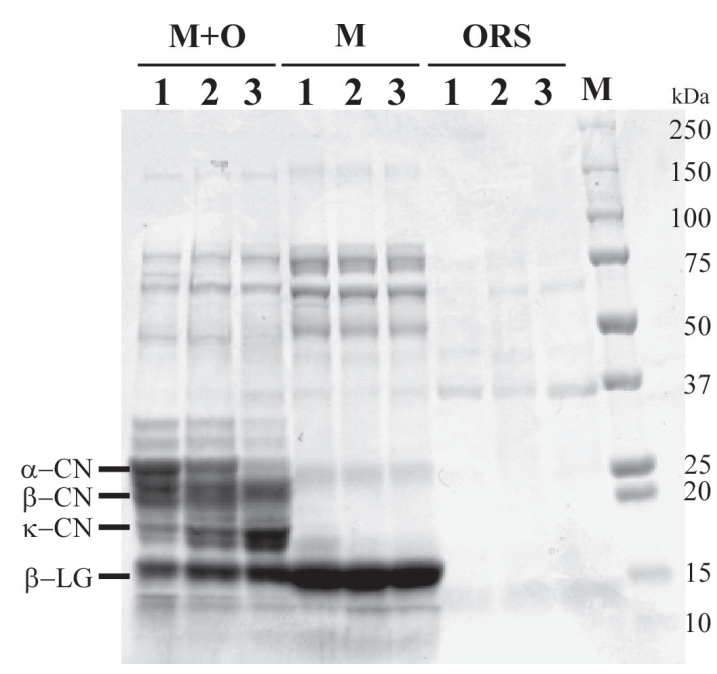

Fig. 3. Protein compositions of the abomasal fluid samples obtained from $50 \%$ oral rehydration salt (ORS)-milk-fed, whole milk-fed, and ORS-fed calves. SDS-PAGE (10-20\% gradient gel) of abomasal fluid samples (10 $\mu \mathrm{g}$ aliquot) obtained from calves $2 \mathrm{hr}$ after feeding 50\% ORS-milk, whole milk, and ORS solution. The gel was stained with Coomassie Brilliant Blue R-250. M+O: 50\% ORS-milk, M: milk, ORS: ORS solution. Numbers mean identification numbers of calves. $\alpha$-CN: $\alpha$-Casein, $\beta$-CN: $\beta$-Casein, $\kappa-C N$ : $\kappa$-Casein, and $\beta$-LG: $\beta$-lactoglobulin.

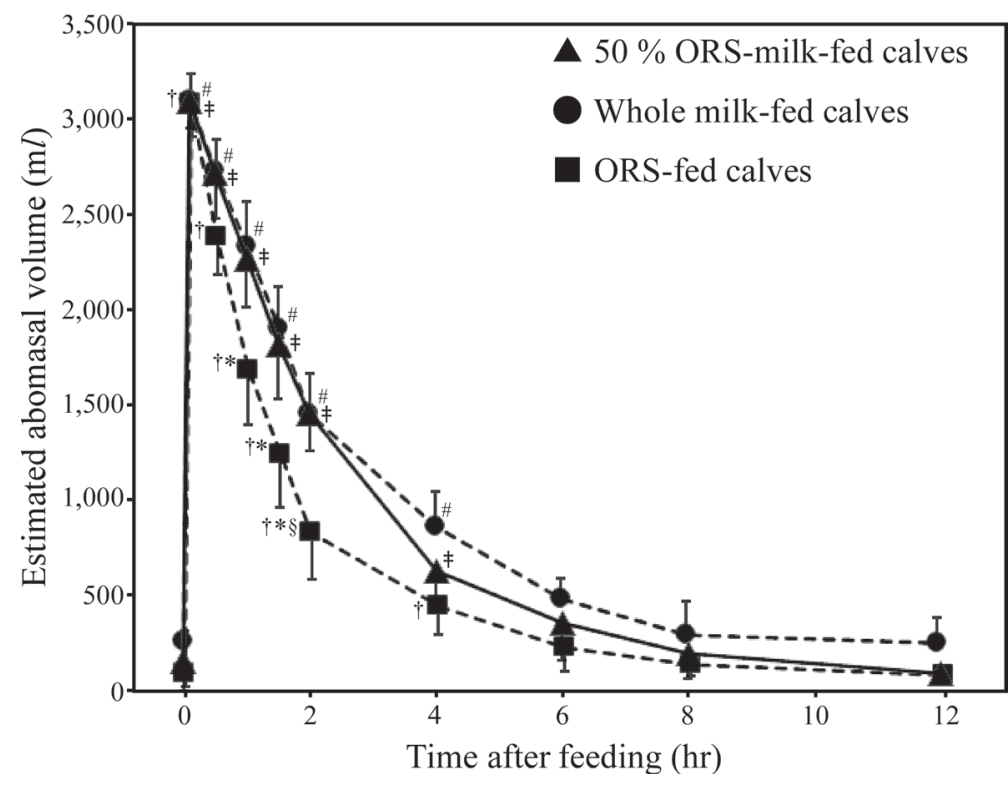

Fig. 4. Temporal changes of abomasal volume in 50\% oral rehydration salt (ORS)-milk-fed ( $\boldsymbol{\Delta})$, whole milk-fed $(\bullet)$, and ORS-fed calves (•). Abomasal volume of $50 \%$ ORS-milk-fed, whole milk-fed, and ORS-fed calves, which were estimated from ultrasonographic images. Data are expressed as mean \pm SD. ${ }^{\S} P<0.05$ compared to the concentration of $50 \%$ ORS-milk-fed calves at the same time. ${ }^{*} P<0.05$ compared to the concentration of whole milk-fed calves at the same time. ${ }^{\ddagger} P<0.05,{ }^{\#} P<0.05$, and ${ }^{\dagger} P<0.05$ compared with before feeding (time $=0$ ) within each group.

anorexia or diarrhea for an evaluation of the treatment effects.

Based on a previous report that the lack of curd formation accelerates the abomasal emptying rate in calves [6, 23], we hypothesized that the abomasal emptying half time was shorter in the $50 \%$ ORS-milk-fed calves than in the milk-fed calves. However, our results show that the abomasal emptying half times were similar in the $50 \%$ ORS-milk-fed calves $(113.5 \pm 14.6$ min) and the milk-fed calves $(113.5 \pm 11.5 \mathrm{~min})$, both of which were within the normal range (104-160 min) for healthy euvolemic 5-13-day-old calves fed $2 l$ of cow's milk [4]. In contrast, different abomasal emptying half times were observed between the 50\% ORS-milk-fed and ORS-fed calves $(70.5 \pm 12.2 \mathrm{~min})$ that were similar to 65 and $75 \mathrm{~min}$ of the calves fed $2 l$ of isotonic glucose solution and hypertonic $\mathrm{NaHCO}_{3}$ solution, respectively [25]. The results indicated that abomasal emptying rates were significantly faster in ORS-fed calves than in the 50\% ORS-milk-fed calves and the milk-fed calves. It has also been reported that calves fed $2 l$ of ORS-milk containing electrolytes such as sodium, potassium, and chloride showed a remarkably slower abomasal emptying rate (260 min) compared to calves fed $2 l$ of milk $(160 \mathrm{~min})$ [4]. Based on these results, we reject our previous hypothesis and suggest that the $50 \%$ ORS-milk causes slow abomasal emptying in calves due to high electrolyte concentrations despite the lack of curd formation.

The formation of abomasal curd functions to digest milk in calves. Curd formation slows the passage of nutrients from the abomasum to the small intestine [6] and enhances feed efficiency, digestibility, and body weight gain [11]. Recently, we showed that curd formation enhances IgG absorption in neonatal calves [16]. Therefore, it is better to apply feeding methods that do not inhibit curd formation in calves. It has also been reported that faster abomasal emptying rates contribute to rehydration in healthy calves $[20,25]$. Since abomasal emptying rates were slower in 50\% ORS-milk-fed calves than ORS-fed calves, we speculate that the diluted milk remained in the abomasum longer than did the ORS solution, and it may not have caused rehydration as quickly as the ORS solution alone. Moreover, 50\% ORS-milk is not suitable for treating dehydrated diarrheic calves; considering reports that abomasal emptying is prolonged in diarrheic calves compared with healthy calves [13], 50\% ORS-milk may further delay the abomasal emptying in the former group. In conclusion, a feeding method using milk diluted $50 \%$ with ORS solution is not recommended for calves because the method impedes, rather than enhances, the functions of milk and ORS solution; ORS solution decreases the function of milk via the inhibition of curd formation while, conversely, a mixture of milk and ORS solution results in prolonged abomasal emptying of the ORS solution. Because the abomasal volume returns to the preprandial level at $6 \mathrm{hr}$ after feeding (Fig. 4), one recommendation is to feed milk and an ORS solution alternately at least $6 \mathrm{hr}$ apart. Feeding ORS powder dissolved in milk directly is also recommended, as reported previously $[4,13]$. 
ACKNOWLEDGMENTS. This work was supported in part by Grant-in-Aid for Scientific Research on Priority Areas from the Japan Society for the Promotion of Science (JSPS) (grant 12J40129, 18K14579). T.M. was supported by a Grant-in-Aid for JSPS fellows.

\section{REFERENCES}

1. Bachmann, L., Schmidt, B., Rauwolf, U., Wenge, J. and Coenen, M. 2012. Change of plasma volume, osmolality, and acid-base status in healthy calves after feeding of milk and water- and milk-based oral rehydration solutions. J. Dairy Sci. 95: 6006-6014. [Medline] [CrossRef]

2. Bachmann, L., Homeier, T., Arlt, S., Brueckner, M., Rawel, H., Deiner, C. and Hartmann, H. 2009. Influence of different oral rehydration solutions on abomasal conditions and the acid-base status of suckling calves. J. Dairy Sci. 92: 1649-1659. [Medline] [CrossRef]

3. Constable, P. 2003. Fluid and electrolyte therapy in ruminants. Vet. Clin. North Am. Food Anim. Pract. 19: 557-597. [Medline] [CrossRef]

4. Constable, P. D., Grünberg, W. and Carstensen, L. 2009. Comparative effects of two oral rehydration solutions on milk clotting, abomasal luminal pH, and abomasal emptying rate in suckling calves. J. Dairy Sci. 92: 296-312. [Medline] [CrossRef]

5. Cruywagen, C. W. 1990. Effect of curd forming of colostrum on absorption of immunoglobulin G in newborn calves. J. Dairy Sci. 73: 3287-3290. [Medline] [CrossRef]

6. Cruywagen, C., Brisson, G. and Meissner, H. 1990. Casein curd-forming ability and abomasal retention of milk replacer components in young calves. J. Dairy Sci. 73: 1578-1585. [CrossRef]

7. Foltmann, B. 1970. Prochymosin and chymosin (prorennin and rennin). Methods Enzymol. 19: 421-436. [CrossRef]

8. Gregory, N. G. 2003. Effect of enhancing curd formation during the first colostrum feed on absorption of $\gamma$ glutamyl transferase by newborn calves. Aust. Vet. J. 81: 549-552. [Medline] [CrossRef]

9. Hallén, E., Lundén, A., Allmere, T. and Andrén, A. 2010. Casein retention in curd and loss of casein into whey at chymosin-induced coagulation of milk. J. Dairy Res. 77: 71-76. [Medline] [CrossRef]

10. Heinrichs, A. J., Wells, S. J. and Losinger, W. C. 1995. A study of the use of milk replacers for dairy calves in the United States. J. Dairy Sci. 78: 2831-2837. [Medline] [CrossRef]

11. Jenkins, K. and Emmons, D. 1982. Evidence for beneficial effect of chymosin-casein clots in abomasum on calf performance. Nutr. Rep. Int. 26: 635-643.

12. Kirchner, D., Schwedhelm, L., Coenen, M. and Bachmann, L. 2014. Dietary influences on the hydration and acid-base status of experimentally dehydrated dairy calves. Vet. J. 199: 251-257. [Medline] [CrossRef]

13. Kirchner, D., Schwedhelm, L., Wenge, J., Steinhöfel, I., Heinrich, C., Coenen, M. and Bachmann, L. 2015. Ultrasonographic imaging of abomasal milk clotting and abomasal diameter in healthy and diarrheic calves. Anim. Sci. J. 86: 929-936. [Medline] [CrossRef]

14. Lorenz, I. 2004. Influence of D-lactate on metabolic acidosis and on prognosis in neonatal calves with diarrhoea. J. Vet. Med. A Physiol. Pathol. Clin. Med. 51: 425-428. [Medline] [CrossRef]

15. Lorenz, I., Fagan, J. and More, S. J. 2011. Calf health from birth to weaning. II. Management of diarrhoea in pre-weaned calves. Ir. Vet. J. 64: 9. [Medline] [CrossRef]

16. Miyazaki, T., Okada, K. and Miyazaki, M. 2017. Short communication: Neonatal calves coagulate first-milking colostrum and produce a large curd for efficient absorption of immunoglobulins after first ingestion. J. Dairy Sci. 100: 7262-7270. [Medline] [CrossRef]

17. Miyazaki, T., Miyazaki, M., Yasuda, J. and Okada, K. 2009. Ultrasonographic imaging of abomasal curd in preruminant calves. Vet. J. 179: 109-116. [Medline] [CrossRef]

18. Miyazaki, T., Miyazaki, M., Yasuda, J. and Okada, K. 2010. No abomasal curd formation in pre-ruminant calves after ingestion of a clotting milk replacer. Vet. J. 183: 205-209. [Medline] [CrossRef]

19. Naylor, J. M. 1992. Effects of electrolyte solutions for oral administration on clotting of milk. J. Am. Vet. Med. Assoc. 201: 1026-1029. [Medline]

20. Nouri, M. and Constable, P. D. 2006. Comparison of two oral electrolyte solutions and route of administration on the abomasal emptying rate of Holstein-Friesian calves. J. Vet. Intern. Med. 20: 620-626. [Medline] [CrossRef]

21. Okada, K., Kato, J., Miyazaki, T., Ikuta, K., Naito, Y. and Yasuda, J. 2009. The evaluation of the curd forming ability of milk replacers. Anim. Sci. J. 80: 12-18. [Medline] [CrossRef]

22. Pedersen, V. B., Christensen, K. A. and Foltmann, B. 1979. Investigations on the activation of bovine prochymosin. Eur. J. Biochem. 94: 573-580. [Medline] [CrossRef]

23. Petit, H. V., Ivan, M. and Brisson, G. J. 1987. Duodenal flow of digesta in preruminant calves fed clotting or nonclotting milk replacer. J. Dairy Sci. 70: 2570-2576. [Medline] [CrossRef]

24. Roussel, A. and Kasari, T. 1991. Using fluid and electrolyte replacement therapy to help diarrheic calves. Vet. Med. 85: 303-311.

25. Sen, I., Constable, P. D. and Marshall, T. S. 2006. Effect of suckling isotonic or hypertonic solutions of sodium bicarbonate or glucose on abomasal emptying rate in calves. Am. J. Vet. Res. 67: 1377-1384. [Medline] [CrossRef]

26. Trefz, F. M., Lorch, A., Feist, M., Sauter-Louis, C. and Lorenz, I. 2012. Metabolic acidosis in neonatal calf diarrhea-clinical findings and theoretical assessment of a simple treatment protocol. J. Vet. Intern. Med. 26: 162-170. [Medline] [CrossRef]

27. USDA 2010. Dairy 2007. Heifer calf health and management practices on U.S. dairy operations, 2007, USDA:APHIS:VS:CEAH, Fort Collins.

28. USDA 2010. Mortality of calves and cattle on U.S. beef cow-calf operations, USDA:APHIS:VS:CEAH, Fort Collins.

29. WHO 2008. Oral rehydration. pp. 349-351. In: WHO Model Formulary 2008 (Stuart, M. C., Kouimtzi, M. and Hill, S. R. eds.), World Health Organization, Geneva.

30. Wittek, T., Constable, P. D., Marshall, T. S. and Crochik, S. S. 2005. Ultrasonographic measurement of abomasal volume, location, and emptying rate in calves. Am. J. Vet. Res. 66: 537-544. [Medline]

31. Ye, A., Singh, H., Taylor, M. W. and Anema, S. 2002. Characterization of protein components of natural and heat-treated milk fat globule membranes. Int. Dairy J. 12: 393-402. [CrossRef] 